\title{
Epidemiología y laboratorios: El eslabón perdido en los planes para estudiar y prevenir la enfermedad infecciosa en Chile
}

\author{
Felipe Cabello C.
}

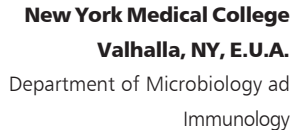

Recibido: 24 de octubre de 2007 Aceptado: 31 de octubre de 2007

Correspondencia a: Felipe Cabello C. cabello@nymc.edu

\section{Epidemiology and laboratories: The missing link on the plans to study and prevent infectious diseases in Chile}

Viral meningitis, hantavirus and Vibrio parahaemolyticus infections are used as examples to demonstrate that important shortcomings and limitations exist in Chile to study the epidemiology of infectious diseases with modern methods. The lack of a national network of well connected local and national microbiology laboratories is one of these important shortcomings. The author summarizes the evolution of the systems and Institutions that deal with the infectious diseases in the world and in Chile.

Key words: Infectious diseases, epidemiology, laboratories network.

Palabras clave: Enfermedad infecciosa, epidemiología, red de laboratorios.
$\mathrm{E}$ n la historia de la humanidad, unos de los grandes logros ha sido lo que se ha dado en llamar el triunfo sobre la enfermedad infecciosa. Triunfo que, como todos sabemos, ha sido incompleto, parcial y también caracterizado por retrocesos, dada la dinámica evolutiva de los patógenos, sus hospederos humanos y animales y el ambiente. Sin embargo, está claro que importantes flagelos como la tuberculosis, el cólera, las fiebres intestinales, la viruela, la poliomielitis y la fiebre puerperal han desaparecido como causas importantes de enfermedad y muerte en varias regiones de la tierra. Los orígenes de estos positivos desarrollos son indudablemente múltiples e incluyen el desarrollo de un Estado moderno, encargado de proteger la salud de la población y una elevación de los niveles de vida, con mejoras substanciales en la calidad de la nutrición, vivienda, saneamiento ambiental y de la educación. Desarrollos científicos relevantes como la postulación de la teoría bacteriana de la enfermedad infecciosa, la enunciación de los postulados de Koch, el descubrimiento y la manufactura de antisueros, vacunas y antimicrobianos y los desarrollos en estadística, epidemiología y ecología, han jugado también un rol importante en esta positiva evolución de las enfermedades infecciosas.

A menudo, en el análisis de los instrumentos que han sido esenciales en el control y la erradicación de la enfermedad infecciosa, se exagera la relevancia que ha tenido en ello, algunos instrumentos tecnológicos como las vacunas y los antimicrobianos, en desmedro de otros avances que parecieran ser de menor conteni- do tecnológico y menos llamativos, desde el punto de vista científico, para la opinión publica y para la política. Entre estos últimos están los desarrollos sociales y tecnológicos relacionados con la aproximación epidemiológica al estudio y control de la enfermedad infecciosa transmisible y que incluyen los fundamentos legales de estos procedimientos, la burocracia profesional que los lleva a cabo, los laboratorios y otros procedimientos que los sustentan, como las redes de captación de información epidemiológica. El estudio de la historia del control de la enfermedad infecciosa transmisible en países como Alemania, E.U.A., Canadá, Francia, a fines del siglo XIX y a comienzos del siglo XX, observará que un instrumento fundamental en este control fue el desarrollo de una burocracia profesional encargada de las pesquisa de la enfermedad infecciosa a lo largo del territorio nacional, sustentada por una red moderna de laboratorios capaces de hacer el diagnóstico de la patología infecciosa con gran certeza. Por ejemplo, de esta época datan en E.U.A. los laboratorios microbiológicos de las ciudades, de los condados y de los estados y los laboratorios nacionales de referencia como los del Centers for Disease Control y los del Departamento de Agricultura, entre otros.

La relevancia que tiene en E.U.A. esta bien estructurada burocracia y su bien conectada red de laboratorios para el control de la enfermedad infecciosa, es apreciada, diariamente, cuando ésta se moviliza de forma ágil para la detección y estudio de diversas epidemias, en las poblaciones humanas y animales. En 
los últimos años, estos sistemas han solucionado rápidamente los desafíos epidemiológicos de enfermedades emergentes, tales como la enfermedad de los legionarios, la enfermedad de Lyme y las infecciones por hantavirus y, diariamente, funciona en la prevención de epidemias producidas por patógenos como Salmonella, Escherichia coli O157 y Staphylococcus aureus resistente a la meticilina. En nuestro país, a pesar de los avances en el control de la enfermedad infecciosa, el desarrollo de una estructura de este tipo es todavía embrionario o casi inexistente e, indudablemente, la población sufre los resultados de estas falencias en cifras de morbilidad y mortalidad por enfermedades que en un país moderno debieran ser casi totalmente prevenibles. Por ejemplo, en los últimos tres años han evolucionado en Chile epidemias de meningitis virales con miles de casos, especialmente, en la Región Metropolitana y en las Regiones $\mathrm{V}^{\mathrm{a}}$, $\mathrm{VIII}^{\mathrm{a}}$ y XIX ${ }^{\mathrm{a}}$, sin que hasta este momento se haya identificado claramente los enterovirus que las provocan ni las rutas de infección para estos virus. La general benignidad de este cuadro pudiera hacer pensar que es irrelevante estudiar su epidemiología para prevenirlo. Sin embargo, los miles de casos de esta patología representan un innecesario sufrimiento humano, que puede ser evitado y su presencia puede indicar fallas en el saneamiento ambiental y en la calidad microbiológica del agua y de los alimentos. Por último, por ser esta patología producida por enterovirus en un país en el que existe un número importante de parálisis fláccidas, su presencia pueden corresponder a fenómenos premonitorios de la presencia de otras patologías relevantes como la poliomielitis, a pesar de la erradicación de esta enfermedad en Chile y de la excelente cobertura de la población con su vacuna.

Las epidemias por Vibrio parahaemolyticus que han asolado repetidamente la Región de Los Lagos y otras del país, tampoco han sido prevenidas o estudiadas de una manera eficiente y su control ha estado basado, principalmente, en el primitivo dictum "comer pescados y mariscos bien cocidos". La aproximación epidemiológica moderna al control de esta patología infecciosa emergente requiere de una vigilancia microbiológica permanente, e in situ, de los mariscos en los lechos de mar de donde éstos se extraen, y el cierre particularizado a la extracción de mariscos de éstos lechos cuando se detecte en ellos aumentos de las concentraciones de $V$. parahaemolyticus. Esta vigilancia epidemiológica debe ser complementada con un control microbiológico de los mariscos después de extraídos, a través de su distribución y antes de que ellos sean consumidos. Todo esto, para confirmar la eficiencia de la cadena de frío y, en general, del manejo de los mariscos después de su extracción, en controlar la multiplicación de los potenciales vibrios que pudieran encontrarse en ellos. El cierre indiscriminado de grandes extensiones costeras a la extracción de mariscos produce grandes e innecesarias pérdidas económicas y sin una vigilancia epidemiológica adecuada de los mariscos durante su distribución y antes de su consumo, puede fracasar en prevenir la infección de la población. Además, el dictum "comer pescado y mariscos bien cocidos" puede se inefectivo en prevenir la infección en poblaciones con una tradición de ingesta de marisco crudos, como sucede en Chile con las ostras, los choritos y las almejas. La implementación de una manera moderna de tratar este problema es esencial para prevenir la infección humana por este vibrio, para entender la epidemiología local de esta patología y para evitar grandes pérdidas económicas en una nación como Chile, que pretende ser una potencia alimentaria.

En los últimos siete años, Chile ha experimentado el deceso por infecciones por hantavirus, de más de 134 personas, cifra que parece elevada si uno la compara con el número de decesos que se han producido por esta enfermedad en la misma época en E.U.A. $(<100$ decesos). Este último país tiene un territorio más extenso que Chile, con endemia para esta infección y tiene también un mayor número de personas potencialmente expuestas a ella. La letalidad de la infección es similar en ambos países. En este caso, el estudio de este problema en Chile, con herramientas epidemiológicas y microbiológicas modernas, también parece ser limitado, ya que no existe un programa sistematizado y una red de laboratorios que, constantemente y de forma sistemática, determine la presencia del hantavirus en los roedores que constituyen su reservorio silvestre, los parámetros de la infección subclínica en humanos y las variaciones del reservorio como resultado de los cambio climáticos y ambientales. Estudios metódicos de esta naturaleza aparecen como imprescindibles para predecir con anticipación la fuerza de infección por hantavirus en las regiones de endemia en el país y para establecer políticas sanitarias que disminuyan los elevados niveles de morbilidad y mortalidad de esta infección. Este tipo de actividades y estudios pueden también ser útiles para prevenir la aparición de zoonosis alternativas con un reservorio silvestre como resultados de la globalización y de cambios ambientales y climáticos.

En los países del Hemisferio Norte, el desarrollo de sistemas e instituciones eficientes para la detección, el estudio y la prevención de la enfermedad infecciosa transmisible de manera moderna, tomó aproximadamente 50 a 70 años. Por ejemplo, en Alemania, país en que se establecieran las bases científicas del estudio de esta patología en las tres últimas décadas del siglo 
XIX, la maduración de estos sistemas se produjo sólo años antes del estallido de la Segunda Guerra Mundial. En E.U.A., en las décadas de los 20 y 30, aún se producían epidemias de fiebre tifoidea y difteria y la desaparición de ellas coincidió con la maduración de las instituciones de inteligencia epidemiológica de los gobiernos locales y del gobierno federal en la décadas de los 40 y 50. El análisis histórico de la evolución de estos sistemas e instituciones indica que estímulos importantes en su instauración fueron la protesta popular frente a epidemias que la ciencia caracterizaba como prevenibles. Esta protesta tuvo variadas formas, incluyendo la asonada callejera y la influencia a través del voto popular sobre los parlamentos y los ejecutivos. La participación de científicos y de médicos y sus organizaciones en la génesis de estos sistemas fue también fundamental, como fuera demostrado, por ejemplo, por las actividades de Rudolf Virchow y Robert Koch en Alemania y William Osler en los Estados Unidos. La participación de intelectuales y políticos también tuvo relevancia en la génesis de estas instituciones, ejemplificado en las obras literarias de Upton Sinclair (E.U.A.), George B. Shaw (Inglaterra) y Enrik Ibsen (Noruega). En Chile, en la década de los 40, 50 y 60 se desarrollaba también una tendencia similar a la descrita en estos países respecto de la creación de sistemas e instituciones que pudieran tratar el problema de la enfermedad infecciosa de forma moderna. Sin embargo, como era de esperar, la suspensión de la democracia el año 1973, el desmantelamiento del Esta- do y de su burocracia que esto produjo, además de las restricciones presupuestarias y de la fragmentación de estas actividades producida por la municipalización, le dieron un golpe fatal al incipiente desarrollo de estos sistemas e instituciones en Chile.

Los ejemplos discutidos más arriba ilustran claramente la urgente necesidad de desarrollar estos sistemas en el país, de manera eficiente y moderna. Está claramente demostrado por países más avanzados en esta materia, que en un contexto de globalización y cambios ambientales y climáticos drásticos, antimicrobianos y vacunas son insuficientes para prevenir y afrontar estos problemas en forma moderna y racional y de manera que se beneficie a la mayoría de la población.

\section{Resumen}

El autor analiza brevemente el estado de tres enfermedades infecciosas de actual relevancia en Chile, incluyendo la meningitis viral, las infecciones por Vibrio parahaemolyticus y las infecciones por hantavirus para demostrar que en el país existe una importante falencia en cómo estudiar estos procesos con modernos métodos epidemiológicos, incluyendo una red nacional de laboratorios que cubra todo el territorio nacional. Además, hace un sumario de cómo se desarrolló el estudio moderno y racional de las enfermedades infecciosas en Chile y en otros países del mundo. 